\title{
Geologic-Geophysical Indicators of the Deep Structure of Zones of Geothermal Anomalies for Allocation of Channels of the Deep Heat and Mass Transfer
}

\author{
R. A. Umurzakov', H. A. Abidov², G. Yu. Yuldashev³ \\ ${ }^{1}$ Tashkent State Technical University, Tashkent, Uzbekistan \\ ${ }^{2} \mathrm{FE}$ "Surhon Gas Chemical Operating Company" Ltd., Tashkent, Uzbekistan \\ ${ }^{3}$ SC "Uzbekgeophysics", Tashkent, Uzbekistan \\ Email: umrah@mail.ru
}

How to cite this paper: Umurzakov, R.A., Abidov, H.A. and Yuldashev, G.Yu. (2017) Geologic-Geophysical Indicators of the Deep Structure of Zones of Geothermal Anomalies for Allocation of Channels of the Deep Heat and Mass Transfer. Open Journal of Geology, 7, 1452-1463.

https://doi.org/10.4236/ojg.2017.79097

Received: August 17, 2017

Accepted: September 26, 2017

Published: September 29, 2017

Copyright (c) 2017 by authors and Scientific Research Publishing Inc. This work is licensed under the Creative Commons Attribution International License (CC BY 4.0).

http://creativecommons.org/licenses/by/4.0/

\begin{abstract}
On the basis of the analysis of field thermogeochemical data along abnormal zones of a thermal stream in the Bukhara-Khiva, oil-and-gas region of the Turan (Tegermen, Chagakul, Shimoly Alat, Beshtepa) was succeeded to obtain important data on a deep structure of sites. Data of gas-chemical and geothermal observations show about confinedness of abnormal concentration of methane to zones of the increased values of the temperature field the measured values of temperatures (Tegermen Square and others). On geoelectric section mines 2-D of inversion of the MT-field depth of $4000 \mathrm{~m}$ are lower, among very high-resistance the chemogenic and carbonate deposits of the Paleozoic is traced the subvertical carrying-out abnormal zone. This zone is identified as the channel of a deep heat and mass transfer with which hydrocarbon (HC) deposits are connected. It is shown that electro-investigation when using a geophysical complex can and has to become "advancing" at exploration by oil and gas.
\end{abstract}

\section{Keywords}

Anomaly of the Thermal Field, Thermogeochemical Data, Juvenile Gases, Channel, Heat and Mass Transfer, Deep Structure, Geoelectric Section, Deposits of Oil and Gas

\section{Introduction}

The idea of existence of channels for deep heat and mass transfer and the con- 
nection with the places of hydrocarbon (HC) accumulation with them appeared and began to develop thanks to group of researchers under the leadership of professor A.A. Abidov.

He and co-authors A.A. Polikarpov, F.G. Dolgopolov [1] [2] noted about "a role of process of a deep heat and mass transfer in formation and location of oil and gas fields in the territory of Uzbekistan". They have developed physics-geological model of process of a deep heat and mass transfer, and structural elements on which there are processes of a deep heat and mass transfer which has been called by "channels of a deep heat and mass transfer" [3]. Within the Turan platform in the territory of the Bukharo-Hiva oil-and-gas region abnormal zones of a thermal stream and channels of a deep heat and mass transfer channels dated for them have been revealed (A. A. Abidov, F. G. Dolgopolov, A. A. Polikarpov and others).

In the published literature possible relationships of cause and effect of a heat and mass transfer widely are discussed with elements of a structure of a subsoil and formation of fluid streams. In work [4] it is shown that in deep parts of crust in the central and east parts of the East European platform there are temperature anomalies at background value of a thermal flow of $60 \mathrm{~mW} / \mathrm{m}^{2}$ which authors consider as the zones of decompaction. They established that on the basis of measurements of temperature anomalies of "liquid injections", zones of their streams and saturation and also gas anomalies can be found [4].

The analysis of the published literature shows that the structure of thermal convection is defined not by balance of heat, but by the distribution of a thermal stream density in the mantle [5]. And they, in turn, can be connected with process by decontamination and a fluid stream, bearing and "a temperature component" [6]. Formation of hydrocarbons and the magnetotelluric phenomena are connected with these processes [7] [8].

The main lines of a heat and mass transfer are defined by multilayered convection, which is most intensive in the external kernel and asthenosphere, and periodic strengthenings of plume activity of Earth. Plumes transfer considerable volumes of $\mathrm{CO}_{2}, \mathrm{H}_{2} \mathrm{O}$ and $\mathrm{K}_{2} \mathrm{O}$ (in the form of carbonatite and water-carbonatite melt), the oxidized silicate substance which is allocated as a result of decontamination of a kernel at his interaction with [9]. Authors of article note that in a stream from depths of Earth the carbon emitted in the form of $\mathrm{CO}_{2}$ and $\mathrm{CH}_{4}$ at volcanic eruptions prevails. Then carbon comes back inside in subduction zones where the carbonate rainfall regulating a superficial cycle [9] is absorbed. There is a question as such mechanism corresponds to new data on hydrogen decontamination, and other elements, prevalence of hydrogen and helium in the general stream of juvenile gases. This question is studied very insufficiently in this connection; it is difficult to agree with the opinion that carbon is predominant from the depths or its absorption through subduction zones.

The new data obtained in recent years show that the decontamination phenomenon from a subsoil of hydrogen is of great importance in the history of evolution of Earth [10]. Explains many problematic issues that didn't answer the 
conditions of "plate tectonics". It is known that provisions of plait tectonics formed "a geodynamic basis" of methods of search of oil and gas fields [11], that won't be coordinated now with new actual data [12]. The new data confirm need to revise of ideas of the reasons and conditions for the formation of oil and gas fields, the scientific basis of methods for the search of hydrocarbon deposits. The mixt genetic model of synthesis of hydrocarbons [1] [2] [3] is directly connected to the physic-geological model of process of deep heat and mass transfer with allocation of "channels" [3], which are the flow of fluid gases.

Examples of existence of similar elements in the earth's crust are known in different regions. However, the mechanism of emergence and structure of the carrying-out zones found subvertical abnormal it isn't studied yet. Only separate works are known in which this problem is discussed.

According to V.A. Shlyakhovsky [7] places of ledges of asthenosphere of a layer in a lithosphere are the most significant for formation of hydrocarbons. The author of article, marks that in this case, the necessary amount of energy exists continuous geological time, and detection of an asthenosphere layer is possible according to seismology and seismic exploration, geoelectricians.

The example of reflection in materials of electroprospecting methods of so-called "sources of heat" in the form of overhangs of an asthenosphere layer was described. In a section the subvertical carrying-out non-uniformity having roots over $2000 \mathrm{~m}$ was selected. The synchronous increase in conductivity from below up is marked, reaching the maximum values around layout of the oil pool. These data show that by geophysical methods the study of the structural zones connected to a heat and mass transfer is quite possible.

There are examples: on the MTZ profile through the Khanty-Mansi field (for many years here good outputs of oil from deposits of the Paleozoic base) the subvertical abnormal carrying-out zone in Paleozoic deposits is noted. Despite existence of scientific publications on a research of the phenomena of a deep heat and mass transfer, questions of the mechanism of formation of "channels" and their deep structure remain not studied. These questions are of great importance for development of scientific-theoretical representations of formation of mineral deposits and methods of their search.

The description of results which reflect features of process, property and elements of a structure of the geological environment of zones of manifestation of channels of a deep heat and mass transfer according to complex researches is provided in this article.

\section{Methodology}

Deep heat and mass transfer-the phenomenon which is genetically connected with processes in the upper mantle.

It is natural to assume that they have to find the reflection in the corresponding geologic-geophysical materials.

The complex of researches on detection of channels of a deep heat and mass 
transfer includes geothermal and gas-chemical shootings, electroprospecting observations, studying of signs of channels of a deep heat and mass transfer on materials of remote sensing.

For specification and specification of features of a deep structure of such zones also materials of seismic prospecting researches have importance.

Geothermal and gas-chemical shootings it was carried out along profiles with measurements of temperature and concentration of gases at depths up to 2 meters. Large-scale mapping of channels of a deep heat and mass transfer within a concrete zone of oil and gas accumulation and the related areas of deep emanations $\left(\mathrm{CO}_{2}, \mathrm{~N}_{2}, \mathrm{H}_{2}, \mathrm{H}_{2} \mathrm{O}, \mathrm{CO}, \mathrm{CH}_{4}, \mathrm{He}\right.$, Ar, etc.) was the purpose of researches.

The entity of gas shooting in relation to an objective, consisted in determination of micro-concentration of juvenile gases in near-surface deposits. On certain squares of the Turan platform gas-chemical shooting was carried out by the staff of institute of geology and investigation of oil and gas fields. The technique of field gas shooting is based on determination in soil air of methane and other hydrocarbons with sampling from slits of 3-4 meters in depth on specially fitted system of profiles [3]. Measurements were carried out in the shots up to 2 meters in depth drilled in the manual way in previously prepared holes of $1 \times 1 \times 1 \mathrm{~m}$ in size. On squares Tegermen and Beshtepa in the Bukharo-Hivinsky oil-and-gas region the two-meter depth of sampling was justified by results of the gas-chromotographic analysis.

As a result of researches it has been established that in a complex these two methods (gas-chemical and geothermal shootings) allow to map areas of juvenile gases and the related distributions of temperature near the land surface.

R. M. Bembel and other [13], G. O. Veliyev [14] claim that deep decontamination surely is followed by the electromagnetic radiation which occurs on subvertical channels. In places of an exit of power whirlwinds (geosolitons) the vertical component of the MT-field, and horizontal electric components opposite prevails, are minimum. Therefore these places are surely mapped by the MTS method.

On squares with the revealed anomaly of a temperature field and geochemical data with the purpose of a study of a depth structure of these sections electroprospecting works were performed by the MTS [15] [16] method. This method was the most effective among other electroprospecting methods. In the territory of the Turan plate, within the Bukharo-Hiva oil-and-gas region field electroprospecting observations by MTS method are executed with use of the "V5 System 2000" equipment of the Canadian company "Phoenix Geophysics Limited". Experience showed that such system of an equipment allows to execute scanning of crust at different frequencies up to the depths of $15 \mathrm{~km}$.

At the heart of the MTS method the energy of electromagnetic radiation having natural origin and caused by interactions of various deep processes is used. Observed anomalies of magnetotelluric (MT) of the field are caused by existence of local not uniformity in a section of the geological environment. MT-fields are 
especially sensitive to vertical changes of a geoelectric section. It allows to study a structure of a section and to allocate objects like channels of a deep heat and mass transfer. These local anomalies are the most important target objects that do MTS to one of the most high-allowing (on lateral) geophysical methods when studying the base and the lower parts of crust.

The following was the main technical characteristics of a measuring system of V5:

- Registration range: the frequency $-400 \mathrm{~Hz}(0.0005 \mathrm{~Hz})$; dynamic-24 discharges of analog-digital converter;

- Record of variations of a magnetotelluric field (MTF) on each point of observations is made on a removable solid-state memory with a capacity of 32-512 of Mbt;

- High reliability and accuracy of registration of the electrical (2E) and magnetic (ZN) MTF components with MTU-5 measuring instruments (2E + ZN) and MTU-2E (2E);

- Operating temperature range, from $-40^{\circ} \mathrm{C}$ to $50^{\circ} \mathrm{C}$;

- The satellite synchronization of measuring instruments providing reliability of measurements irrespective of distance;

- Automated computer processing at all stages of operations: from registration before receiving geoelectric sections $2 \mathrm{D}$ and 3D.

Process of hands-off processing of field electroprospecting materials was executed in two stages. First stage: processing of the field digital records MT-fields, by means of the programs SSMT-2000, MtEditor, WinGlink, conversion of files of ranges to files of the international EDI format (ranges) and PLT (impedances)-for import to the database and interpretations on WinGlink.

At the second stage computer and geological interpretation was made. By preparation of results for interpretation cuts and cards of resistance $\left(R_{t}\right)$, phases $\left(F_{t}\right)$, magnetic parameters, induction vectors on profiles and also geoelectric 1-D, 2-D models and 1-D, 2-D inversions of the MT-field consistently were under construction.

At interpretation of materials MTS the given GIS and drillings located on the studied objects and near them have been attracted. Comparison of coal mines 1-D of inversions to data of GIS show good convergence of geological models of various environments according to wells and results of processing of MTS.

\section{Results and Discussion}

On the basis of results of the gas-chromotographic analysis on the site Tegermen on basic profiles T-I and T-II have received (A. Tulanov and other) 276 definitions of $\mathrm{CH}_{4}, \mathrm{C}_{2} \mathrm{H}_{6}, \mathrm{C}_{2} \mathrm{H}_{4}, \mathrm{O}_{2}, \mathrm{~N}_{2}$ and $\mathrm{CO}_{2}$ in gas tests and 63 definitions of $\mathrm{CH}_{4}$, $\mathrm{O}_{2}, \mathrm{~N}_{2}$ and $\mathrm{CO}_{2}$ in tests of the subsoil. On a profile T-I two sites with the content of methane in gas tests more than twice exceeding a standard deviation on pickets of 90 - 210 (Figure 1) and on conditional pickets of 6 - 9 (Figure 2) are allocated. 


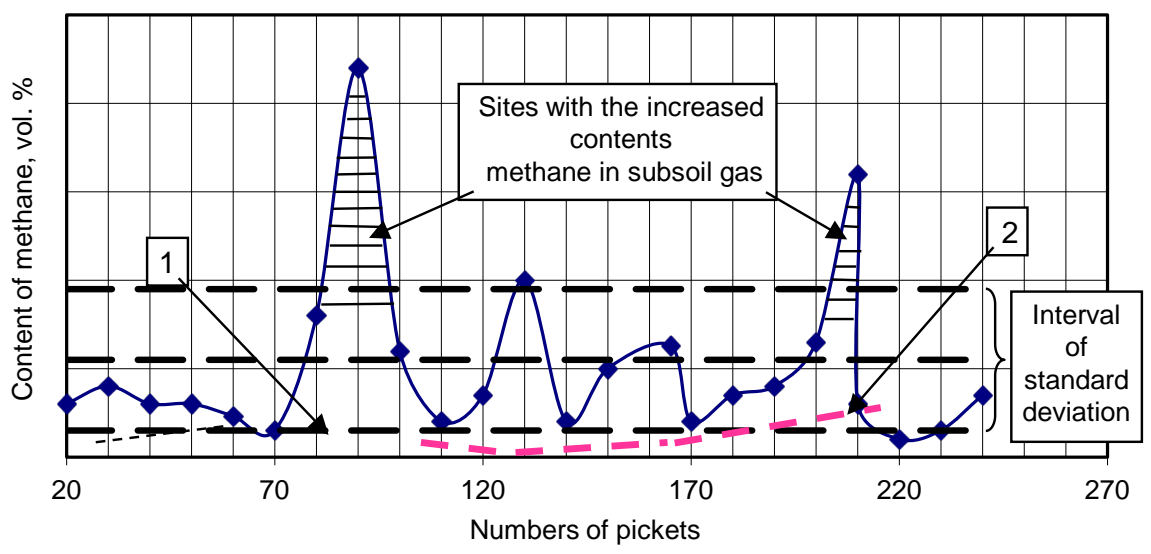

Figure 1. Distribution of methane in subsoil gas (1) and adsorbed under the soil (2) sites Tegermen (Bukhara-Khiva oil-and-gas region) on the T-I profile.

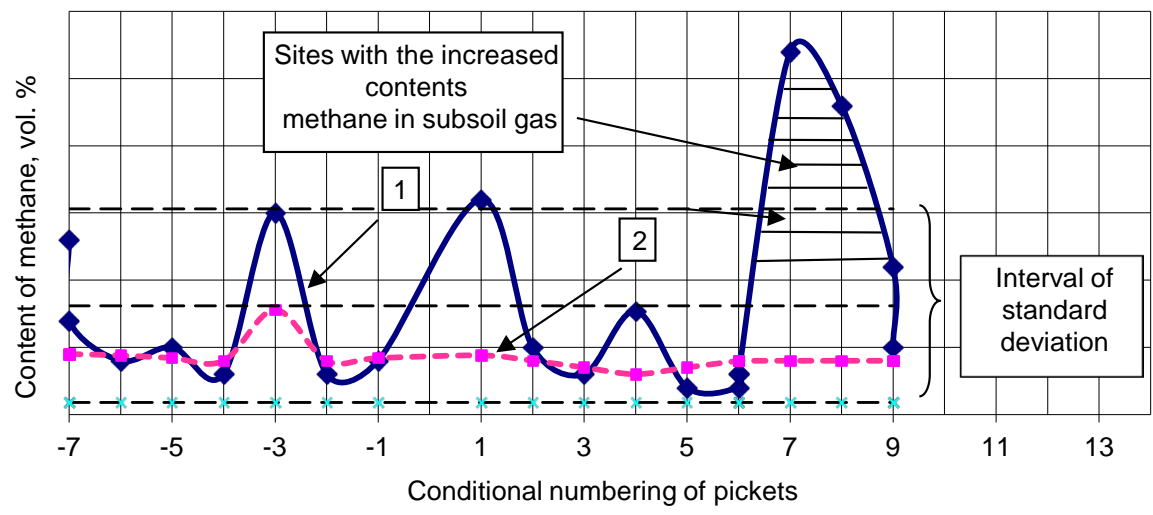

Figure 2. Distribution of methane in subsoil gas (1) and adsorbed under the soil (2) sites Tegermen (Bukhara-Khiva oil-and-gas region) on the T-II profile.

The comparative analysis of these gas-chemical and geothermal observations shows about confinedness of abnormal concentration of methane to zones of the increased values of the temperature field. In the Figure 3 the schedule of distribution of the measured values of temperatures on a profile T-II at Tegermen square is provided.

Compliance of abnormal values of concentration of methane and temperature on conditional pickets 7 - 9 on the T-II profile at Tegermen square is visible. Such coincidence is observed also on other areas of Bukhara-Hiva oil-and-gas region such as Beshtepa, Urtabulak, Tashkuduk, Guzhayli, Muradkuduk.

As a result of geophysical surveys it was set that almost all known fields of the researched territory stand out on sections of apparent resistances, phases of an impedance and 1-D inverses [15] [16] clearly.

On sections of magnetotelluric parameters high electrical differentiation of the researched geoelectric section in which $6-7$ geoelectric horizons in deposits of the Mesozoic-Cenozoic are surely selected is marked. At the same time anomalies of resistance were received almost over all known fields. The revealed anomalies have irregular shape. In a section of sedimentary thickness high resistances characterize chemogenic and carbonate deposits and also hydrocarbon deposits. 


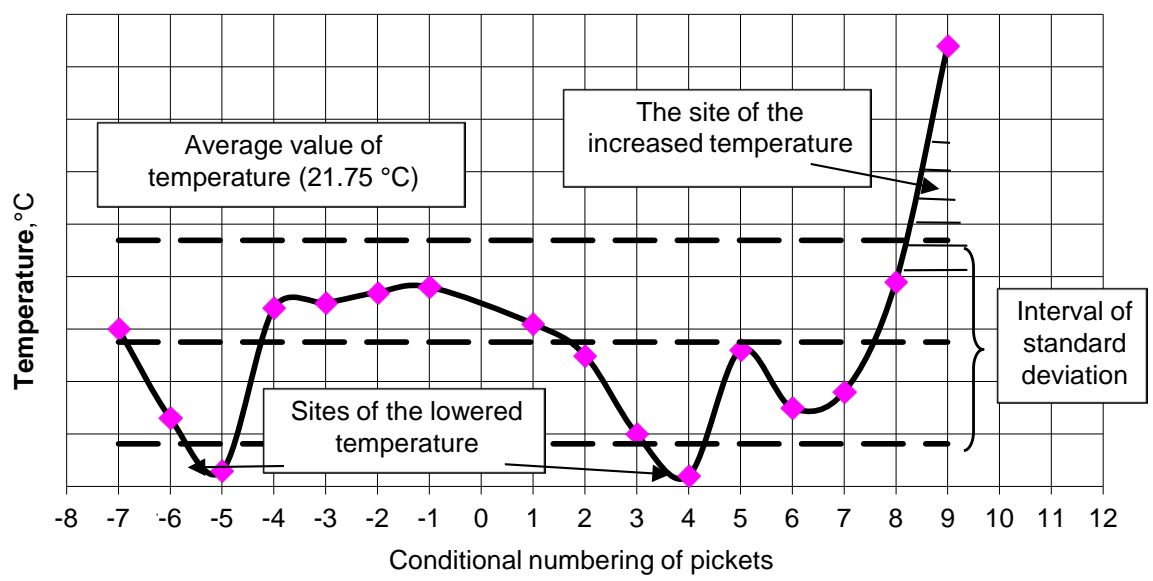

Figure 3. Distribution of temperature at a depth of $2 \mathrm{~m}$ from terrestrial the surfaces of the site Tegermen on a profile T-II.

Have low resistances-the clay and sandy-argillaceous deposits saturated in a varying degree with the mineralized water.

Section 1-D of inversion enough differentially reflects morphology of surfaces of the reflecting horizons $(\mathrm{RH})$ lower cretaceous $-\mathrm{T}_{2}$, the lower anhydrites $-\mathrm{T}_{5}$ and carbonate deposit- $\mathrm{T}_{6}$. In the Figure 4 comparison of results of seismic exploration of MOGT-2D and geoelectric section 1-D of inversions on the seismic profile 44,080,807 crossing the Oydin and search structure Karakamar is given. Immersion of the horizons of $\mathrm{T}_{2}$ and $\mathrm{T}_{3}$ (the isoline of the seeming resistance $\rho_{\tau}=5.0 \div 6.3 \mathrm{Om} \cdot \mathrm{m}$ ) from the southwest on the northeast to a zone of the lowered resistance characteristic of deep tectonic violation is well reflected in a geoelectric section. Sharp rising of the horizon on location corresponds to structure Oydin who is limited by tectonic violation in the north. Three more zones of the lowered resistance indicate existence of tectonic violations here.

At a depth of H-2150 m on method common depth point (CDP) T5 (Figure $4(\mathrm{a})$ ) and also on isolines $\mathrm{p}_{\mathrm{r}}=\mathrm{P}, 0$ of Om.m (Figure 4(b)) is shown anticlinal structure Karakamar. She is hypsometric lower than structure Oydin. Under these structures in a section the hereditary imaginative zone of reduction of specific electric resistance with a depth is noted.

On the basis of the carried-out electroprospecting works the specified tectonic elements of a southeast part of the Beshkent deflection, a southeast part of Dengizkul and Mubarek raisings; the Uchkyr-Pitnyak shaft are made. The location of structures Oydin, Marvarid, East Ramazan, Karakamar, Topilma, Murodota is specified.

On the basis of field researches along abnormal zones of a thermal stream it was succeeded to obtain important data on a structure of these sites (Figure 5(a)) on the P-I profiles (Tegermen square and Chagakul), P-II (also Chagakul) and also on the P-III profile (to Beshtepa square-Kumsultan crosses nourth Alat square).

On geoelectric Section 2-D of inversion of the MT-field where depth of a research of 15,000 m, since depth of $4000 \mathrm{~m}$, among very high-resistance breeds of 


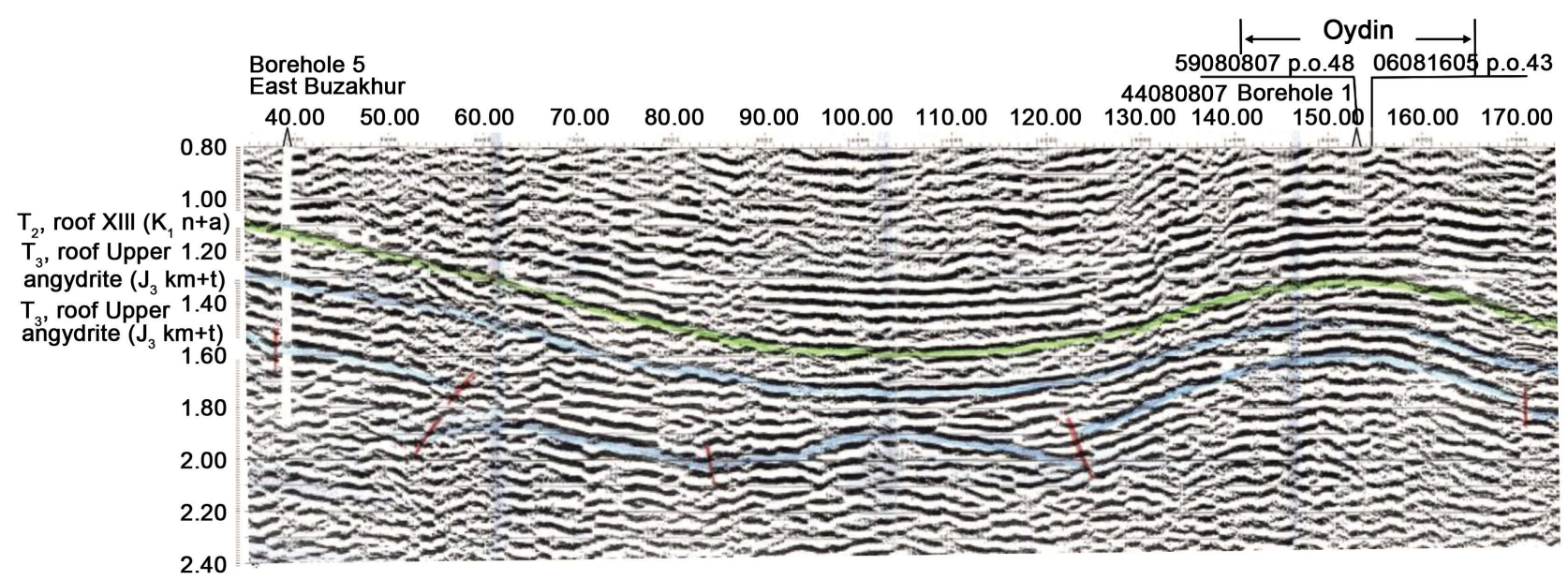

(a)

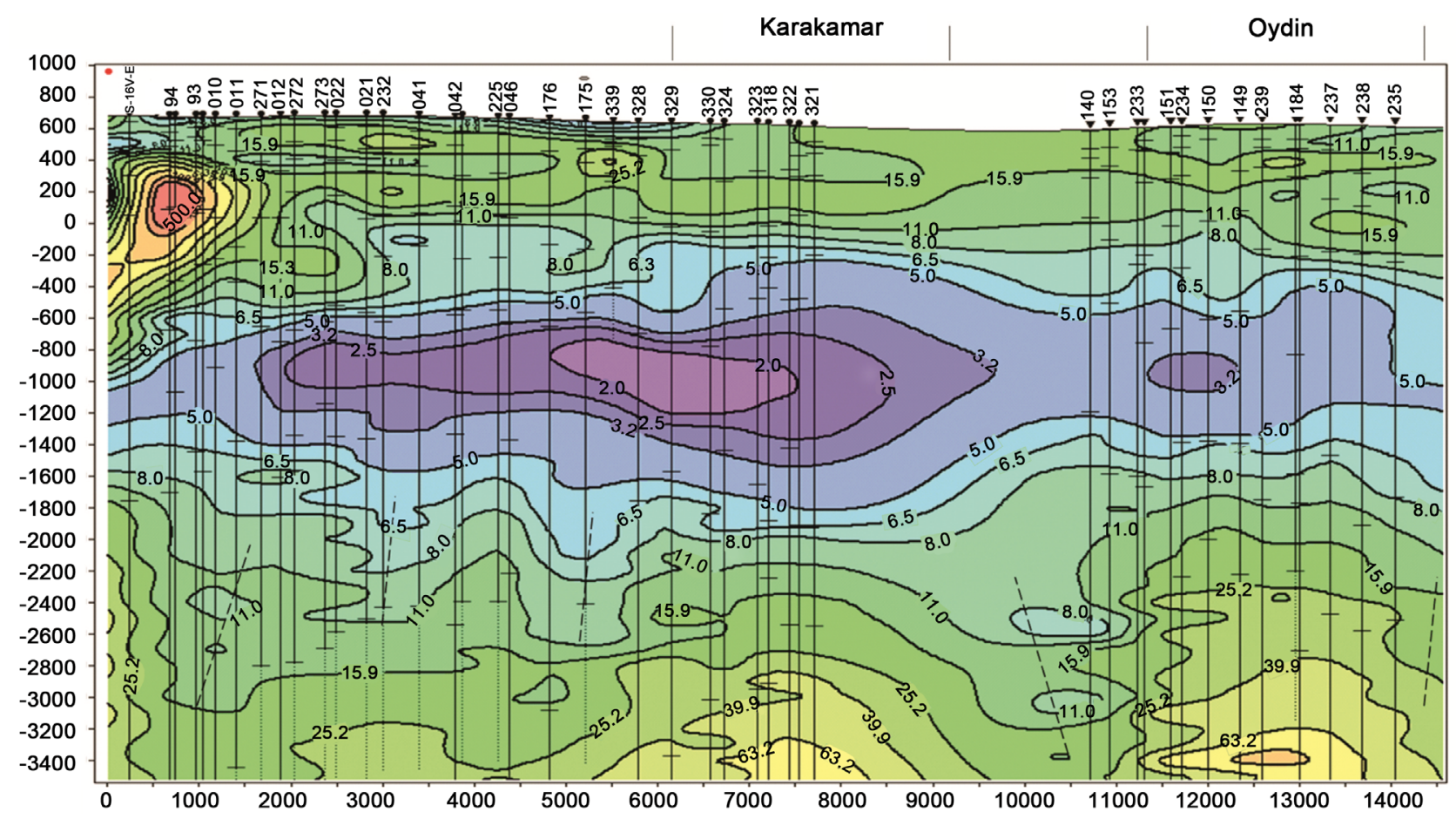

(b)

Figure 4. Comparison of results of MOGT-2D (a) and geoelectric cut 1-D of inversions (b) on a seismic profile 44,080,807 through Oydin area and structure Karakamar.

the Paleozoic is traced the subvertical carrying-out abnormal zone (Figure 5(b)). This subvertical channel is identified as channel deep heat and mass transfer.

In geoelectric Section 1-D of inversion of the MT-field on a profile 73,090,307 Shirinkuduk squares (Figure 6), crossing certain gas fields, in the range of depths of $6000 \mathrm{~m}$ and 10,000 $\mathrm{m}$, are allocated a subvertical abnormal zone which corresponds to pre-Jurassic educations. Since $6000 \mathrm{~m}$ in depth her branching-in southern Zheynov and northern by Pirnazar the directions is observed. Above on a section the abnormal zone reaches depths of $3000 \mathrm{~m}$ and $3500 \mathrm{~m}$ (corresponds to the lower part of a sedimentary cover). It is appropriate to note that the 


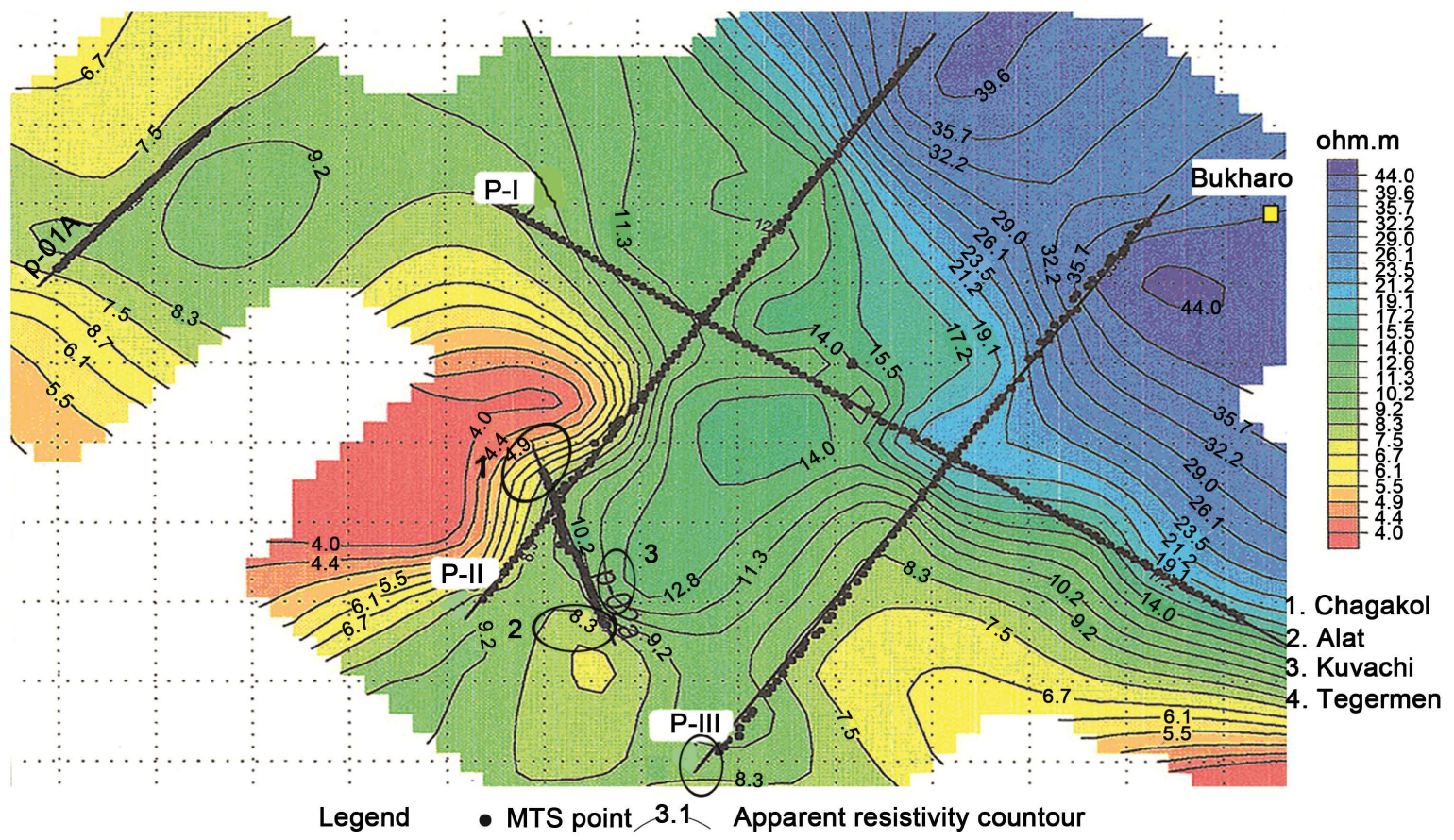

(a)

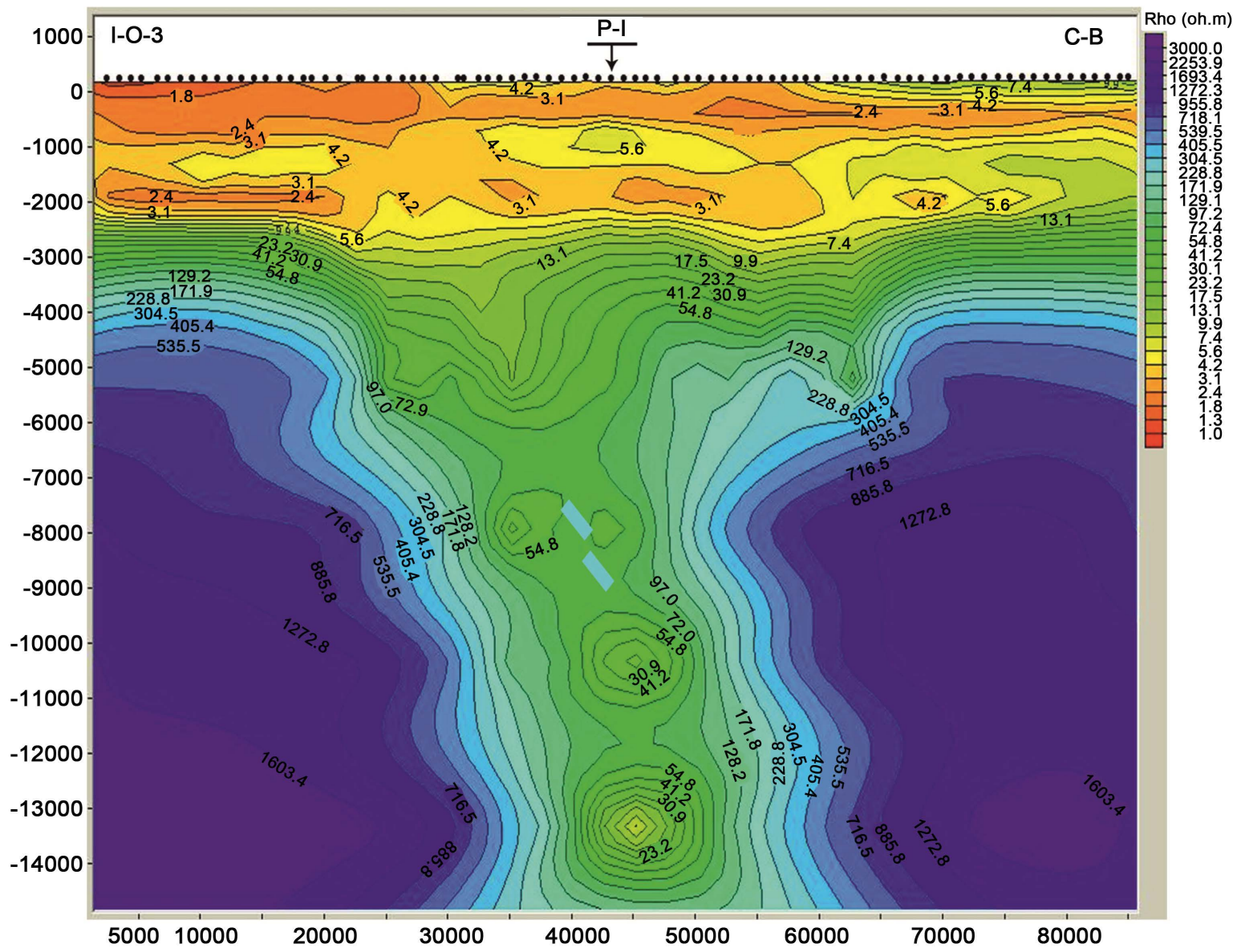

(b)

Figure 5. Results of electroprospecting works at Chagakul square and Tegermen of Bukharo-Hiva region. 


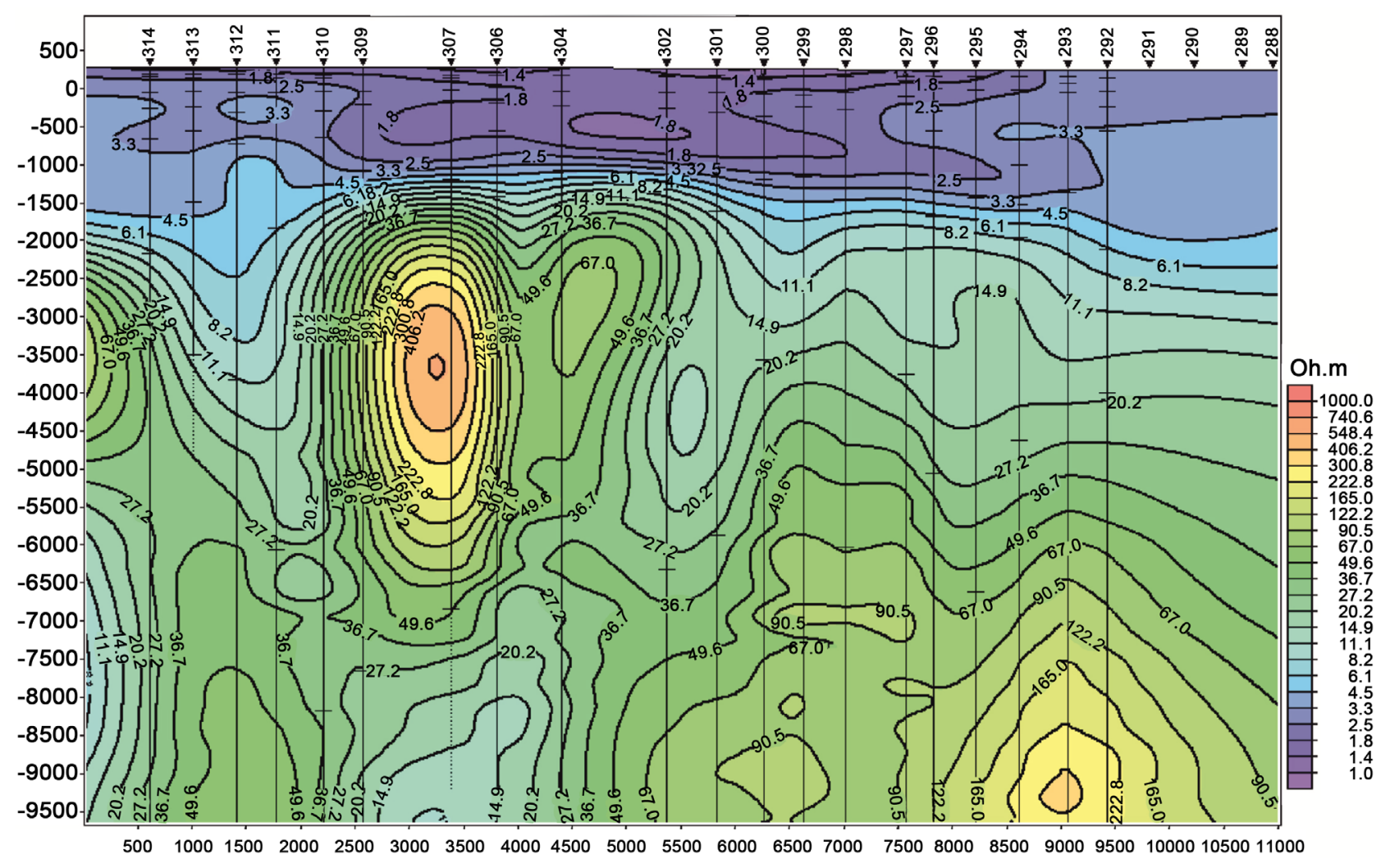

Figure 6. Cut 1-D of inversions across profile 73,090,307 Shirinkuduk.

productive well of Pirnazar square is on a branched part of a subvertical abnormal zone. The well has opened productive XV-HP the horizon the Kellovey-Cimmerian of deposits of jura, and in the range of depths of 2616 - $2678 \mathrm{~m}$ good outputs of gas are received.

Follows from the above that the high-allowing large-scale electroprospecting works 3D-the MTS method allow to map the geodynamic structural zones which are channels deep heat and mass transfer and in the expected zones violation in a complex with thermogeochemical shooting to predict favorable congestion hydrocarbon zones with definition of perspective sites for concentration in prospective areas of detailed seismic prospecting works $2 \mathrm{D}$ and $3 \mathrm{D}$.

It is established that the carrying-out abnormal zones are connected with vertical channels of permeability in pre-Jurassic educations and stretch for big depths. The mechanism of formation of such zones contacts the ascending gases and fluid stream leading to change of physical properties of sedimentary breeds thereby creating an areola of the increased resistance. Besides it has been established what in a sedimentary cover of influence of deposits of hydrocarbons is shown in increase in resistance.

\section{Conclusions}

For the first time in world scientific practice of the issue of allocation of channels of a deep heat and mass transfer is discussed by thermogeochemical and geo- 
physical methods.

The majority of publications are devoted to theoretical questions of a thermal stream, convection and heat exchange in various materials, to determination of thermal parameters of these or those materials and breeds and also the related magnetotelluric phenomena.

Despite extensive discussion of mechanisms of thermal convection in the world literature, the idea of existence of channels of a deep heat and mass transfer in Earth subsoil, and communications of places of formation with them and congestion hydrocarbon has appeared and began to develop since the end of the past and the beginning of this century (1997-2005) in Uzbekistan, thanks to work of group of researchers under the leadership of professor A.A. Abidov.

It is established that the main channels of heat exchange in the lower cloak are thermochemical plume. At the same time the form of the channel of a plume has the cylindrical form with deviations in places of the maximum influence of a horizontal mantle current. In the channel of a plume there are independent convective cells, and for plume towards horizontal currents there is a temperature trace. Time of fusing and rising of a plume from border a kernel-mantle to the basis of a lithosphere is defined in 3 - 5 million years.

Taking into account high efficiency, mobility, a smaller material capacity and a possibility of studying of a geoelectric section from a day surface to the crystal base and deeper horizons, electro-investigation with use of the V5 complex in a geophysical complex can and has to become "advancing".

\section{Acknowledgements}

Authors of article note that in receiving materials, their processing and the analysis in different years A. A. Abidov, A. A. Polikarpov, L. P. Sorokotyaga, A. Tulanov, U. Rakhmatov and also the staff of the Center of processing and the analysis of geological data of TashSTU took part. Authors express all of them sincere gratitude.

\section{References}

[1] Abidov, A.A. and Dolgopolov F.G. (2004) Basic Model of the MixtGenetic Scheme of Natural Synthesis of Hydrocarbons. Reports of the Russian Academy of Sciences. No. 3.

[2] Abidov, A.A., Dolgopolov, F.G. and Tilyabayev, Z. (2005) MixtGenetic Model of Formation of Oil and Gas in Crust. Materials of the Second International Conference "Geodynamics of Oil and Gas Bearing Basins", Moscow, 19-21 October 2004, 36-42.

[3] Abidov, A.A. (2010) Genesis of Oil and Gas and Technique of Search of Their Accumulation Site. Publishing House of Academy Sciencs of Uzbekistan, Tashkent, $258 \mathrm{p}$.

[4] Khristoforova, N.N., Khristoforov, A.V. and Muslimov, R.K. (2000) Temperature Distribution and Anomalies in the Crystalline Basement of the Tataria Arch. Physics and Chemistry of the Earth, Part A: Solid Earth and Geodesy, 25, 597-604.

[5] Gordiyenko, V.V., Gordiyenko, I.V. and Logvinov, I.M. (2007) The Thermal Field 
and Objects of High Conductivity in Bark and the Top Mantle of Ukraine. Physics of Earth, No. 4, 28-34.

[6] Dobretsov, N.A. and Shatsky, A.F. (2012) Deep Cycle of Carbon and Deep Geodynamics: A Role of a Kernel and the Carbonatite of Fusions in the Lower Mantle. Geology and Geophysics, No. 11, 1455-1475.

[7] Shlyakhovsky, V.A. (2010) Identification of Not Uniformity in a Lithosphere as Sources of a Formation of Deposits of HC. The Scientific and Technical Magazine of Georesurs, 2, 35-38.

[8] Berdichevsky, M.N. and Dmitriyev, V.I. (2009) Models and Methods of a Magnetotellurics. Scientific World, Moscow, 680 p.

[9] Korchagin, V.I., et al. (2002) Decontamination of Earth: Geodynamics, Geofluids, Oil and Gas. Materials of the International Conference, Moscow, 20-24 May 2002, 123-126.

[10] Larin, V.N. (2005) Our Earth (Origin, Structure, Structure and Development of Initially Hydrogenium Earth). Agar, Moscow, 242 p.

[11] Sheyin, V.S., et al. (1986) Geology and Geodynamics Oil and Gas of Areas of the South of the USSR. Works of Institute (VNIGNI), No. 255. Nedra, Moscow, 232 p.

[12] Herndon, J.M. (2016) New Concept on the Origin of Petroleum and Natural Gas Deposits. Journal of Petroleum Exploration and Production Technology, 7, 341-352. https://doi.org/10.1007/s13202-016-0271-5

[13] Bembel, P.M., Megery, B.M. and Bembel, S.R. (2003) Geosolitons: Functional System of Earth, Concept of Investigation and Development of Fields of Hydrocarbons. II. 2nd Edition, Vector, Tyumen, 224.

[14] Veliyev, G.O. (2002) Geodynamic Activity of Bowels of the Earth and Her Influence on a Section Oil-and-Gas Bearing. Geophysics, No. 5, 57-59.

[15] Yuldashev, G.A. and Sorokotyaga, L.P. (2015) Ways of Increase in Efficiency of Electroprospecting Works When Forecasting Efficiency Revealed and Search of New Perspective Objects on East Part of the Fergana Hollow. The Bulletin of the National University (NUUZ), No. 3/1, 134-141.

[16] Yuldashev, G.A. and Sorokotyaga, L.P. (2015) Identification of Structures of Complex Structure a Complex of Geophysical Surveys in the Beshkentsky Deflection. The Bulletin of the National University (NUUZ), No. 3/1, 141-146.

\section{Submit or recommend next manuscript to SCIRP and we will provide best service for you:}

Accepting pre-submission inquiries through Email, Facebook, LinkedIn, Twitter, etc. A wide selection of journals (inclusive of 9 subjects, more than 200 journals)

Providing 24-hour high-quality service

User-friendly online submission system

Fair and swift peer-review system

Efficient typesetting and proofreading procedure

Display of the result of downloads and visits, as well as the number of cited articles

Maximum dissemination of your research work

Submit your manuscript at: http://papersubmission.scirp.org/

Or contact ojg@scirp.org 